\title{
Turismo e patrimônio cultural sob o olhar do sujeito-morador: Uma leitura do bairro da Praia Grande, São Luís, Maranhão (Brasil)
}

\section{Tourism and the cultural heritage under the subject-inhabitant gaze: A reading of Praia Grande District, São Luis, Maranhão (Brasil)}

\author{
Karoliny Diniz Carvalho (CARVALHO, K. D.) ${ }^{*} \mathrm{e}$ \\ Maria de Lourdes Netto Simões (SIMÕES, M. de L. N.) ${ }^{* *}$
}

\begin{abstract}
RESUMO - O artigo objetiva analisar a visão dos moradores do bairro da Praia Grande na cidade de São Luís, Maranhão (Brasil), sobre as políticas públicas de revitalização da área e o aproveitamento turístico do seu patrimônio cultural. Utiliza a abordagem qualitativa, mediante pesquisa bibliográfica e de campo. Por meio de uma amostra não-probabilística por intencionalidade, realizaram-se entrevistas semi-estruturadas junto à comunidade no intuito de identificar e discutir os reflexos da relação entre turismo e patrimônio na dinâmica sociocultural local. Constatou-se a ausência de participação dos moradores nas ações de preservação e de desenvolvimento turístico do bairro da Praia Grande, além de conflitos em torno da apropriação do patrimônio local. O estudo aponta para a necessidade de inserir os moradores no processo de valorização do patrimônio a fim de conciliar os usos sociais e turísticos, possibilitando, assim, a sustentabilidade na relação turismo e patrimônio.
\end{abstract}

Palavras-chave: Turismo; Patrimônio Cultural; Bairro da Praia Grande; Sustentabilidade.

ABSTRACT - This article aims to analyze the inhabitants' view of Praia Grande District in São Luis, Maranhão, about the area revitalization public policies and the tourism employment of its cultural heritage. Its approach is the qualitative one, using the bibliographical and the field research. Through a non-probability sample by intentionality, it was accomplished semistructured interviews with the community in order to identify and discuss the consequences of the relationship between tourism and heritage in the local sociocultural dynamics. It was found the absence of inhabitants participation in activities of preservation and tourism development in the Praia Grande District, besides the conflicts over the ownership of local heritage. The study highlights the need of inserting the inhabitants in the local heritage valorization process in order to conciliate the social and the tourism uses, thus enabling the sustainability in the relationship between tourism and heritage.

Key words: Tourism; Cultural Heritage; Praia Grande District; Sustainability.

\footnotetext{
* Graduação em Turismo pela Universidade Federal do Maranhão (UFMA). Mestranda em Cultura e Turismo pela Universidade Estadual de Santa Cruz (UESC), Ilhéus, Bahia (BA). Bolsista da Fundação de Amparo à Pesquisa do Estado da Bahia (FAPESB). Endereço Postal: Rua Barão do Rio Branco, Quadra I, número 14, Sítio Leal. CEP: 65045-340 - São Luís - Maranhão (Brasil). E-mail: karol27_turismo@yahoo.com.br

** Graduação em Letras pela Faculdade de Filosofia de Itabuna. Especialização em Literatura Portuguesa pela Universidade Federal da Bahia (UFBA). Especialização em Literatura Brasileira pela Pontifícia Universidade Católica de Minas Gerais (PUCMG). Doutorado em Estudos Portugueses pela Universidade Nova de Lisboa (Portugal). Coordenadora do Grupo de Pesquisa Identidade Cultural e Expressões Regionais - ICER, na Universidade Estadual de Santa Cruz (UESC). Consultora de projetos relacionados à literatura, cultura, turismo, memória e identidade. Endereço Postal: Avenida Lomanto Júnior, 712, Pontal. CEP: 45654-000 - Ilhéus - Bahia (Brasil). E-mail: ticassimoes@uol.com.br
} 


\section{INTRODUÇÃO}

A paisagem urbana configura-se nos traços materializados sob a forma de ruas, praças, avenidas, casarões e edifícios de um dado momento histórico, de uma determinada época, os quais sendo ressignificados pela comunidade sobrevivem ao tempo (SANTOS, 1996). Pode-se comparar a cidade a um livro, cada um de seus elementos é como uma página que se abre, descrevendo o passado de quem a construiu e de quem a habitou, quem sobre ela legislou, deu-lhe o nome; traçou seus desenhos, determinou os modelos de suas casas, as dimensões de suas ruas, o lugar apropriado para o cemitério, para as igrejas, para os hospitais, feiras, conventos, o prostíbulo, as favelas, as mansões, os lugares-memória.

Além desses elementos materiais, a cidade pode ser representada em outros níveis, ou seja, nas manifestações culturais predominantes, nas atividades econômicas, no seu patrimônio natural. A dinâmica a que está sujeita uma cidade representa a própria dimensão cultural, cujo significado remete aos sujeitos que compartilham os mesmos significados, formando aquilo que se denomina comunidade de sentidos, “[...] habitação, habitar, portanto, expressam um grau superior e constante de apropriação. Essa relação contínua, permanente, cotidiana, demorada e que o tempo adensa, é que cria as condições mais favoráveis para a fruição do patrimônio ambiental urbano". (MENESES, 2006, p. 39).

A cidade é uma força social presente no imaginário dos seus habitantes, capaz de gerar sentimento de identificação e solidariedade. A cidade, assim, não se dá aos que a ocupam como um espaço abstrato ou como lugar destinado a apenas certos usos técnicos, tais como circular, trabalhar, morar. Ela possui uma realidade espessa de sentidos particulares relacionados aos movimentos mais tênues do sujeito.

Fruto de uma obra coletiva, a cidade guarda em si vários significados. Os valores culturais atribuídos ao espaço urbano decorrem da ação social. Não estão detidos nos objetos, mas são oriundos da dialética das relações sociais. A identidade, a significação, a importância dos objetos, o reconhecimento dado a algumas coisas e valores provêm do que lhes é imposto pelo grupo social. Assim, um profundo dialogismo se inscreve na rota que o sujeito traça pela cidade. Esse diálogo ancora-se, por um lado, nas ações públicas de preservação do patrimônio que determinam os sentidos que irão circular 
nesse espaço, e do outro, nas práticas que os cidadãos exercem a partir desses códigos, reelaborando-os.

Tendo como cenário o bairro da Praia Grande, localizado no centro histórico da cidade de São Luís, Maranhão (Brasil), o presente artigo objetiva analisar os reflexos das políticas de preservação e da atividade turística no cotidiano dos moradores. Para tanto, fez-se necessário esquadrinhar as relações comunitárias, os processos patrimoniais implicados nesse espaço urbano e as repercussões que deles se originaram. Segundo Souza (1997, p. 109), numa leitura urbanística “[...] é necessário não só perceber a forma, entender seu conteúdo, como associar e desvendar as formas de pensamento que estão por trás de suas representações". Lembra, portanto, "que é preciso ver forma, conteúdo e pensamento no texto da cidade".

Enquanto procedimento metodológico elegeu-se a abordagem qualitativa, a qual se caracteriza pelo tratamento e análise de dados que expressam as subjetividades, os simbolismos, atitudes e crenças dos grupos sociais. Na visão de alguns autores (BARROS e LEHFELD, 2000; APPOLINÁRIO, 2009; MINAYO, 1994) a pesquisa de caráter qualitativo pressupõe o contato direto do pesquisador com o objeto ou realidade investigada, buscando o entendimento das relações, dos processos e dos fenômenos sociais de modo a revelar os significados, os detalhes e minúcias impossíveis de serem analisados sob a perspectiva quantitativa.

Por meio de uma amostra não-probabilística por intencionalidade (DENCKER, 1998), realizaram-se entrevistas semi-estruturadas junto à comunidade do bairro da Praia Grande, perfazendo um total de cinquenta moradores entrevistados. A coleta de dados efetivou-se no mês de fevereiro de 2010, durante três dias na semana, em locais de intenso fluxo de transeuntes, tendo por base um roteiro de perguntas semiestruturado, possibilitando, assim, o posicionamento dos sujeitos em relação à temática levantada pela pesquisa.

Diante do exposto, inicialmente apresenta-se uma discussão sobre turismo e patrimônio cultural, contextualizando as ações públicas de preservação e revitalização do patrimônio cultural do bairro da Praia Grande. Em seguida, o artigo aborda as impressões dos moradores acerca da relação turismo e patrimônio cultural, sobretudo no que tange aos conflitos simbólicos que emergem a partir da apropriação turística da área, assim como seus reflexos no cotidiano da comunidade local. 
Posteriormente, e com base nas entrevistas realizadas, expõem-se algumas considerações acerca da sustentabilidade das áreas patrimoniais para o turismo, enfatizando alguns princípios ou diretrizes que podem ser utilizados para se promover uma gestão sustentável do patrimônio cultural no bairro da Praia Grande.

\section{TURISMO E PRESERVAÇÃO PATRIMONIAL NA PRAIA GRANDE}

O patrimônio cultural está intrinsecamente relacionado às vivências de uma comunidade e, essas, interconectadas ao bairro, ao centro histórico, à cidade. Nesse sentido, os espaços urbanos contêm em si referências para determinado grupo social na medida em que se revestem de valores simbólicos, memorial que remete às diferentes histórias, memórias e identidades locais.

Há ligação entre a coletividade e o lugar, onde os saberes e fazeres comunitários continuam sendo apreendidos e ressignificados. $\mathrm{O}$ patrimônio cultural interage com o momento presente, sendo então referencial histórico e identitário e suporte das manifestações culturais da vida cotidiana.

O patrimônio cultural urbano consiste, portanto, no resultado da acumulação de esforços de uma ou várias gerações na elaboração de uma sociedade que se expressa pelo modo de construir, mas onde, também, estão imbricadas suas maneiras de viver, de relacionar-se com os seus pares e com o ambiente que a cerca. Um patrimônio cultural é, pois, uma construção que depende de uma trama social como as das políticas de preservação, que são elementos-chave nesse processo que ressignifica os lugares:

\footnotetext{
As cidades não são concebidas de uma só vez e por um só autor, senão ao longo de séculos e por múltiplos e sucessivos atores, que a cada geração se apropriam de elementos antigos, descartam outros, criam novos e reinterpretam tudo criando novos sentidos. Toda cidade é, assim, ao mesmo tempo, histórica e contemporânea, uma obra aberta e permanentemente em transformação (MAGNANI, 2006, p. 65).
}

Propiciando a construção e reconstrução das identidades, reproduz a vida humana em todas as duas dimensões, enquanto retomada dos lugares, recriação de pontos de encontro e busca de identidade na relação com o outro. Os espaços urbanos apresentam marcos para a tessitura da identidade, como destaques no imaginário que 
cada morador constrói da cidade e que contribuem para a familiaridade das pessoas com o entorno. Marcos que servem também para fixar e fortalecer um centro ou uma centralidade em torno do qual a cidade se organiza (LYNCH, 1988).

$\mathrm{Na}$ sociedade contemporânea, a revitalização de áreas urbanas torna-se uma alternativa para o desenvolvimento sócio-econômico. $\mathrm{O}$ valor e o significado que o patrimônio adquire enquanto enunciador de diferentes histórias, memórias e identidades tornam-se imprescindíveis para o processo de formatação dos bens patrimoniais em produtos ou atrações turísticas. Por meio dos patrimônios culturais, a atividade turística promove trocas recíprocas entre os grupos sociais e o reconhecimento da diversidade cultural, em meio ao processo de globalização e à tendência a padronização do capital simbólico. Essa constatação permite compreender o turismo como uma experiência que propicia a descoberta do eu e do outro numa perspectiva de integração, com repercussões positivas no exercício de alteridade.

Nesse sentido, o turismo cultural pode auxiliar no processo de revalorização do patrimônio, por meio do estímulo a implantação de projetos e ações de revitalização que tencionam a sua incorporação à dinâmica contemporânea, e do aumento da percepção dos moradores sobre a importância da história, da cultura e das tradições enquanto elementos de reafirmação da identidade local.

O turismo cultural pode conferir maior visibilidade ao patrimônio, reforçando as singularidades dos elementos que integram os espaços urbanos - monumentos, edificações históricas, logradouros, práticas e manifestações socioculturais - ao tempo em que amplia a percepção da cidade como lócus de criação coletiva, dinâmica e mutável. Assim, a inserção de localidades no circuito do turismo cultural oferece possibilidades de revitalização do acervo arquitetônico através da valoração e da potenciação de determinados elementos e atributos constitutivos do patrimônio cultural local.

Entretanto, decorre dessa valorização implicações no que se refere à transformação do patrimônio-referência em patrimônio-recurso (ARANTES, 1999), ou seja, à distinção que se opera entre o valor de uso do patrimônio e seu valor de troca. Segundo o autor na denominada "economia simbólica do patrimônio", ocorre uma distinção entre o valor do bem patrimonial enquanto símbolo, isto é, como o conjunto 
de referências e sentidos enraizados na vida coletiva, e enquanto alegoria, vinculado ao prazer estético e lúdico proporcionado pelo turismo.

Dentre as possíveis interferências negativas do turismo no tocante ao patrimônio cultural, destacam-se a descaracterização das manifestações populares, dos valores e tradições locais na perspectiva de atender às necessidades do consumo visual e estético dos visitantes; a cenarização do patrimônio histórico e arquitetônico com o consequente remanejamento da população residente das áreas de interesse turístico e, ainda, alterações na sociabilidade dos moradores em relação à presença de turistas em sua comunidade (SOTRATTI, 2010).

Essas evidências apontam para a cidade de São Luís, no Estado do Maranhão, onde a dinamização do turismo tem propiciado um ascendente processo de restauração e revitalização do acervo arquitetônico na área do centro histórico da cidade. O Programa de Preservação e Revitalização do Centro Histórico de São Luís - PPRCH/SL, denominado projeto Reviver, possui como suas principais diretrizes promover a manutenção do uso residencial, fomentar a geração de emprego e renda, incentivar as manifestações culturais, estimular melhorias na infra-estrutura da área, além de preservar o patrimônio arquitetônico ambiental urbano, reintegrando-o à dinâmica social e econômica da cidade (SILVA, 1997).

Especificamente no bairro da Praia Grande, essas ações direcionam-se no sentido de elevar turisticamente aquele espaço urbano, e são alicerçadas pela forte conotação do aspecto senhorial-colonial que o seu perímetro urbano evoca. A importância desse espaço urbano remonta aos séculos XVII, XVIII e XIX, períodos em que a cidade de São Luís vivenciou um tempo de efervescência sócio-econômica e cultural. Com seu posterior declínio, resultou num espaço cuja representatividade - em temos de manutenção dos aspectos tradicionais da cultura local e de preservação do acervo arquitetônico - alicerçou a sua incorporação à atividade turística, sobretudo nos anos de 1990.

Por meio das ações do programa de preservação e revitalização do patrimônio cultural, o bairro da Praia Grande passou a adquirir maior representatividade. Isso, pois a cidade vem incorporando seus monumentos antigos e os (re) apropriando, no intuito de assumir determinada funcionalidade no presente. A culminância desse processo deuse com a elevação de São Luís à condição de Patrimônio Cultural da Humanidade. A 
obtenção do título conferiu notoriedade a São Luís, contribuindo decisivamente para a captação de fluxos turísticos para a localidade.

Inserido no processo de produção e consumo cultural em escala globalizada, o conjunto de casarões e prédios coloniais do centro histórico tornou-se símbolo de diferentes memórias e ao mesmo tempo um produto turístico. O trânsito de visitantes e os benefícios oportunizados pelo turismo refletiram-se na introdução de novos valores no acervo arquitetônico local. Por sua vez, o patrimônio cultural do bairro da Praia Grande vem sofrendo constantes reformulações visando sua inserção no mercado turístico, articulando dessa forma a preservação dos valores social e simbólico do patrimônio cultural e sua adequação aos novos usos.

Com o advento do turismo, o lugar Praia Grande anteriormente vinculado estritamente às atividades de vivência, trabalho ou moradia pelos residentes, alterou o seu significado, com reflexos diretos nos valores a ele atribuídos e, sobretudo, no tipo de relacionamento entre os moradores e seu patrimônio. As transformações na dinâmica sociocultural em virtude do turismo influenciaram diretamente a percepção dos moradores em relação aos impactos dessa atividade sobre o patrimônio cultural, e notadamente em seu nível de comprometimento em relação à preservação dos bens patrimoniais.

\section{A RELAÇÃo TURISMO E PATRIMÔNIO CULTURAL: A PERSPECTIVA DO MORADOR}

A compreensão da dinâmica do bairro da Praia Grande só adquire sentido quando se problematizam as memórias individuais e coletivas, sociais e históricas, ou seja, quando o patrimônio cultural relaciona-se com as questões e os desafios travados na atualidade, e a comunidade questiona-se, reporta-se e se projeta.

As primeiras impressões que vieram à tona na fala dos moradores entrevistados remontam ao passado colonial da cidade, período em que, na visão deles, o centro histórico de São Luís e suas atividades comerciais apareciam de forma mais dinâmica, entrelaçando-se com o cotidiano das ruas boêmias onde habitavam a burguesia mercantil. No passado, o bairro da Praia Grande enquanto centro comercial reservava 
aos seus moradores determinados lugares para encontros e sociabilidade. Adentrando ao cotidiano, o tempo passava lento e impregnado de histórias.

Em determinados enunciados, o bairro da Praia Grande emerge como ponto de espera, de chegada e de partida, simbolizando a alma da cidade. Na perspectiva dos moradores entrevistados, o bairro da Praia Grande não representa apenas o marco da evolução da cidade de São Luís, mas adquire um significado especial por ser o local onde são tecidas as diferentes relações socioculturais, e onde se situam os lugares de convívio, do comércio, das festas sagradas e profanas, e das interações turísticas. Emerge também como cenário de disputas pela moradia, pela preservação das tradições e pela melhoria da qualidade de vida dos cidadãos.

Em seu percurso mnemônico pelo bairro da Praia Grande, os moradores reconstruíram o tempo vivido, reelaborando e remanejando, por meio do tom das palavras, dos silêncios, pausas e inflexões, fragmentos da cidade que aos seus olhos se desfaz, se constrói e se solidifica em outras bases. Sugeriram ainda alterações, projetando, assim, soluções espaciais e políticas para a revitalização do espaço em que transitam:

\footnotetext{
As múltiplas e freqüentes intervenções (nas cidades), inevitavelmente desfiguradoras dos contextos existentes, constroem novos cenários urbanos, tornando os referentes instáveis e transitórios. As paisagens urbanas, paradoxais e difusas, desintegram os suportes da memória e desativam os mecanismos de reconhecimento. Além de espaço em que emergem movimentos, a cidade constitui, sobretudo, um espaço em movimento (SCHULZ, 2008, p. 206).
}

Acompanhando o ritmo de transformação da paisagem urbana, o bairro mudou de sentido: do lugar de ficar foi se tornando espaço para consumir. A fragmentação das cidades em tempos de hibridismo, pós-modernidade e globalização traduz um sentimento de estranhamento nos sujeitos, deslocando o que era íntimo, familiar aos moradores em algo diferente, extraordinário, ou não-habitual. Na contemporaneidade, os casarões da Praia Grande tornaram-se sedes de órgãos das administrações públicas estaduais e municipais ou foram refuncionalizados, passando a abrigar equipamentos relacionados ao turismo, tais como agências de viagens, casas de cultura e museus, bares, restaurantes, lojas de artesanato e de souvenirs. 
Enquanto o centro histórico adentra num novo ritmo e uma nova racionalidade que recria as identidades na Praia Grande, redefine-se o tempo social do morador, tornando-o híbrido, fragmentado, multifacetado. A cidade que se apresenta para eles é uma cidade sem memória, mercantilizada, que abstrai os anseios da comunidade. $\mathrm{Na}$ visão de alguns entrevistados, essas novas representações atribuem ao morador a função de espectador, provocando tensões e dissonâncias inerentes ao processo de mercantilização dos espaços urbanos para o turismo. As relações sociais e espaciais se transformam no fluxo do tempo e não ocorrem sem conflitos, contradições e resistências.

Ao mesmo tempo o bairro apresenta-se como lugar de fronteira, de articulações de agentes internos e externos, os quais evidenciam as relações entre centralidade e marginalidade, inclusão e exclusão, ou seja, movimentos "de passagem e significados que são posicionais e relacionais, sempre em deslize ao longo de um espectro sem começo nem fim" (HALL, 2003, p. 33).

Considerando os fatores sócio-econômicos e devido ao fluxo de atividades turísticas vem ocorrendo um aumento da violência na área: assaltos, assassinatos, furtos, estupros. Evidenciou-se nas informações obtidas junto a alguns dos entrevistados que a segurança do turista é mais importante que a do morador, o nível de atendimento prestado ao turista deve ser melhor do que aquele prestado aos membros da comunidade. Para o atendimento dos moradores há um pequeno posto policial que funciona até a meia-noite.

O problema de estacionamento no centro histórico é uma questão que ainda permanece com muitas deficiências, apesar da construção de alguns estacionamentos em volta da área, os usos instalados no local, como equipamentos culturais, instituições, favorecem a concentração de pessoas e a geração de tráfego, criando uma demanda de áreas para estacionamento. As intervenções pontuais e os investimentos realizados em infra-estrutura, na recuperação de imóveis para uso cultural buscando a preservação e revitalização da área, não levaram em consideração questões relativas à acessibilidade.

A especulação imobiliária também foi apontada pelos moradores como uma das principais mudanças decorrentes da política de patrimonialização por que vem passando o local, o que representa para eles a perda da propriedade ou posse das construções coloniais. A comunidade entrevistada afirmou que boa parte dos casarões foi comprada 
por franceses, portugueses, italianos, dinamarqueses, que os transformaram em objetos para o consumo turístico:

Cada vez mais está ficando menos morador no bairro, e a gente vê que são estrangeiros procurando se quer vender os casarões e se oferecendo pra fazer pousadas, hotéis, restaurantes, bares e eu sempre falo pro pessoal do bairro: eu nasci há 55 anos. Há 56 anos aqui era um bairro cheio, todas as casas eram cheias de gente. Hoje nós somos poucas pessoas, o que acontece é isso aqui futuramente vai ser um bairro só de festa, só pra turista vir passear ${ }^{1}$.

Ocorre ainda uma disputa simbólica e discursiva entre os gestores do patrimônio local e os moradores pela apropriação e o uso efetivo do acervo arquitetônico. Os órgãos de preservação do patrimônio cultural com base no disposto pela Lei do tombamento (SILVA, 1997) determinam as regras de uso do espaço público, tendo por objetivo equalizar as necessidades humanas e a disposição uniforme e legível do espaço urbano. Esses são exemplos de como a questão do tombamento é inserida no âmbito das relações sociais. Nela se reproduzem os conflitos de interesses, de posições e visões de mundo:

\footnotetext{
Emanando de centros de decisão que transcendem o plano local, as medidas de acautelamento necessariamente repercutem (ou causam impactos) sobre os sentidos/sentimentos localizados reforçando-os, redefinindo-os, legitimandoos ou, negativamente, silenciando-os (ARANTES, 1999, p. 133-134).
}

As experiências específicas de habitar uma área tombada e que apresenta uma série de restrições quanto ao uso social do patrimônio levaram alguns dos proprietários de casarões coloniais a recriarem seus espaços de moradia e seus usos familiares, desenvolvendo estratégias para driblar as fiscalizações, imprimindo modificações nos imóveis, como por exemplo, a inserção de placas comerciais para conferir maior visibilidade às atividades comerciais e a adaptação de casarões para o estacionamento de veículos.

A reconstrução simbólica do espaço e do tempo no bairro da Praia Grande se contradiz com a situação da maioria dos moradores tradicionais que não possui os recursos necessários para a manutenção e conservação do patrimônio edificado, contribuindo para reduzir a sua qualidade de vida. Muitos moradores assistem com

\footnotetext{
${ }^{1}$ R. S. Professora aposentada.
} 
pesar o processo de deterioração e de abandono das construções históricas, muitas das quais representam os únicos elos com seus antepassados.

Os conflitos evidenciam-se e refletem-se, por exemplo, na projeção que os moradores e planejadores urbanos tecem para aquele espaço urbano. Por um lado, os gestores públicos mediante a revitalização objetivam o caráter funcional do lugar e, do outro, os moradores, que almejam a sua incorporação ao espaço revitalizado e, consequentemente, a elevação de sua qualidade de vida. Para os moradores entrevistados o bairro da Praia Grande, embora possua um valor simbólico e de uso, não supre as demandas contemporâneas em termos de serviços específicos, tais como atendimento médico, farmácias, supermercados e delegacias.

Argan (2005) analisa a contradição existente entre o discurso modernizante de revigoramento dos centros históricos como alternativa econômica para as comunidades e a atuação dos agentes responsáveis pelas políticas de preservação dos núcleos patrimoniais. Para o referido autor, a sobreposição de interesses contribui para o esvaziamento e a cenarização dessas edificações, ao tempo em que promove o alijamento da população tradicional dessas áreas:

\begin{abstract}
A paralisia econômica e social dos centros históricos é quase inevitável [...] o engarrafamento do trânsito e o acúmulo de automóveis estacionados estão em contradição com as antigas estruturas; o processo de abandono, sobretudo por parte das gerações jovens, é rápido [...] A substituição das velhas classes populares e pequeno-burguesas por novas classes ricas provocam verdadeiras falsificações, não só porque os edifícios são geralmente esvaziados, reduzidos a simples fachada, reestruturados em seu interior, mas também porque as próprias classes originais constituem um bem cultural que deveria ser protegido (ARGAN, 2005, p. 79-80).
\end{abstract}

A reivindicação popular na busca pela preservação do patrimônio cultural conduziu também à mobilização e organização comunitária por meio de uma associação dos moradores. Seu objetivo consiste em promover uma maior interlocução entre os segmentos populares e os gestores públicos, no sentido de assegurar melhorias estruturais, sociais, econômicas e culturais para o bairro.

No entanto, observa-se a necessidade de maior envolvimento e participação da comunidade local na revitalização e no gerenciamento dos bens culturais pela atividade turística, no sentido de evitar a formação de um espaço urbano descontextualizado em relação à dinâmica sociocultural local. Constatou-se que a maior parte dos moradores 
não conhece ou não sabe indicar as ações que estão sendo efetivadas pelos órgãos públicos para a preservação do patrimônio cultural da Praia Grande.

Assim, há a necessidade de estabelecer uma maior aproximação entre os órgãos de preservação do patrimônio local e os grupos comunitários que estabelecem, por meio de suas práticas cotidianas e das relações de sociabilidade, uma leitura particularizada da realidade sócio-econômica e cultural do lugar Praia Grande. Assegurar maior representatividade dos moradores no que tange ao planejamento urbano e às práticas preservacionistas amplia o significado do patrimônio e contribui para a cidadania cultural.

Outro aspecto destacado que demonstra como a institucionalização do patrimônio cultural do bairro pode ocasionar interferências negativas para os moradores refere-se à priorização das reformas e melhorias que são feitas nas fachadas e nas ruas, naquilo que os turistas têm acesso à vista, em detrimento dos interiores das residências e dos locais mais afastados das visitações. Inscreve-se nesse contexto também a problemática da autenticidade do patrimônio ambiental urbano diante das novas exigências de refuncionalização dos acervos arquitetônicos, com a sua adaptação a novos usos e funções.

Tendo em vista o alargamento do conceito de patrimônio cultural, destaca-se a necessidade de se conservar as características e transformações sofridas pelo bem cultural ao longo da sua trajetória, entendido como lócus da criatividade e da dinamicidade dos diferentes atores sociais. Cada lugar possui uma dinâmica sociocultural própria, sua cultura, valores e costumes. Desse modo, o espaço urbano é produzido conforme essas relações mais amplas, num processo articulado à produção geral da sociedade. A revitalização consiste, nesse caso, em considerar não somente os aspectos materiais das cidades históricas, mas as diferentes identidades, valores e memórias construídos ao longo do tempo (LOUREIRO; SANTIAGO, 2009).

Os entrevistados consideraram que a preservação do patrimônio equivale à manutenção de suas características originais, "para mim, preservar é reformar o que está destruído, mas conservando a forma"”; "é cuidar, para que mantenha a sua própria característica", "cuidar, restaurar sem danificar a forma original". ${ }^{4}$ Quando interpelados

\footnotetext{
${ }^{2}$ K. G. Comerciante, 45 anos.

${ }^{3}$ D. C. C. Aposentada, moradora do bairro da Praia Grande há 52 anos.

${ }^{4}$ R. D. B. Comerciante, 78 anos, vive no bairro há 48 anos.
} 
a respeito da revitalização do bairro da Praia Grande, todos os entrevistados afirmaram a sua importância como instrumento de manutenção dos bens patrimoniais, por um lado, e do outro, como fator que permite à comunidade do Centro Histórico reconhecer o significado dessa área para o fortalecimento da memória e da identidade local. Esse reconhecimento torna-se perceptível na seguinte informação verbal:

Revitalizar é promover o nosso patrimônio, é importante para manter viva a história da Praia Grande, nossas ruas, casarões, têm muita história, muita coisa para ser mostrada para as gerações futuras. Lembrar que uma parte da memória da cidade está guardada aqui, nos casarões coloniais, nos azulejos. Eu acho que revitalizar é importante por trazer à tona nossas raízes". 5

Ainda, parcelas significativas da população entrevistada atribuíram somente ao Estado a tarefa de preservação e conservação do acervo arquitetônico. Foram apontadas práticas, como limpeza das ruas, evitar a depredação, manutenção das características originais da fachada dos casarões, dentre outros. No entanto, esses discursos não se legitimam na prática, na medida em que se torna evidente os exemplos de pichação dos prédios, ausência de preocupação em depositar o lixo em locais adequados, além de práticas de vandalismo, que comprometem a integralidade do patrimônio da cidade.

Alguns entrevistados informaram que as ações de revitalização, empreendidas pelos órgãos públicos locais, poderiam ocasionar maiores benefícios para a comunidade, atendendo aos seus anseios e expectativas. Para esse grupo de moradores, a preservação poderia ser alcançada mediante a refuncionalização do acervo arquitetônico, sobretudo por meio da função habitacional. É o que revela a informação verbal de uma moradora: "Preservar é cuidar das coisas, por exemplo, tem um monte de prédios velhos aí que prometeram restaurar para servir de moradia à comunidade e até hoje nada. Se isso acontecesse todos seriam beneficiados com a preservação do patrimônio". 6

Dotar o patrimônio de novos usos pode contribuir para a valorização das produções culturais de uma determinada comunidade, permitindo a manutenção das construções arquitetônicas, renovando a paisagem urbana e tornando-a funcional para os seus habitantes. Os moradores, por seu turno, devem participar do processo de amalgamação dos recursos culturais para o turismo, contribuir para a disseminação de sua memória e para a revitalização dos espaços urbanos testemunhos de sua história.

\footnotetext{
${ }^{5}$ B. S. do S. Vendedor, 36 anos.

${ }^{6}$ M. da C. Comerciante, 50 anos, vive há 47 anos no bairro.
} 
Nesse âmbito, a cidade será vista "como construção histórico-cultural, como patrimônio de seus moradores, como espaço de memória” (MENESES, 2004, p. 86).

Outros moradores consideraram que a revitalização do bairro contribuiu para potencializar seu potencial de atratividade turística: “é importante para manter o bairro bonito, para atrair turistas", "torna-se interessante para a conservação de nossa história e receber melhor os turistas". 8 Para os moradores o turismo é visto como fator econômico, considerando as oportunidades de geração de emprego e renda e de promoção da cultura local, sobretudo quando da realização de eventos, que atraem um público significativo de espectadores para o bairro.

Embora o turismo não se constitua a única atividade exercida para a obtenção da renda familiar, dada a sazonalidade imanente ao setor, ressalta-se que o turismo tem reforçado a vocação comercial que sempre esteve presente no bairro da Praia Grande, fato que também estimula a continuidade de atividades ligadas a esse setor. No entanto, os entrevistados não se referiram ao turismo como elemento propiciador da sustentabilidade dos bens materiais e simbólicos existentes na área. Essa constatação expressa a predominância de uma representação restrita acerca do fenômeno turístico, ou seja, os moradores não visualizaram as repercussões positivas que o turismo pode ocasionar nos aspectos social, ambiental, cultural e político do bairro da Praia Grande.

Parte-se do pressuposto de que o turismo pode contribuir para o revigoramento e a preservação dos centros históricos, na medida em que este prescinde da manutenção dos bens patrimoniais enquanto substrato e apreensão da experiência turística. Nesse patamar, a inserção de localidades no circuito do turismo cultural oferece possibilidades de revitalização do acervo arquitetônico através da valoração e da potenciação de seus elementos e atributos constitutivos (MENESES, 2004).

Os locais de visitação turística no bairro restringem-se àqueles que rememoram determinados fatos e acontecimentos da história e da memória oficial, isto é, institucionalizados pelos órgãos de preservação patrimonial da cidade, ao tempo em que os locais de afetividade indicados pelos moradores entrevistados não integram efetivamente os roteiros de visitação turística da cidade.

Nesse patamar, os roteiros turísticos divulgados e comercializados demonstram por meio de seus conteúdos e imagens, por exemplo, os elementos do patrimônio

\footnotetext{
${ }^{7}$ I. L. Professora, 48 anos, moradora há 34 anos.

${ }^{8}$ J. L. S. Feirante, 52 anos, morador da Praia Grande há 20 anos.
} 
cultural local que se tornam passíveis de apreciação. A valorização do patrimônio consagrado pelo marketing turístico contribui para a seletividade do olhar do visitante, na medida em que elege arbitrariamente os locais da cidade envoltos pelo signo da representatividade. Nos mapas turísticos oficiais, "a indicação de seus pontos mais significativos, mostram os caminhos que unem setores, realçam ruas e revelam monumentos da cidade investidos simbolicamente, ao passo que apagam outros" (FREIRE, 1997, p. 71).

Na dinâmica da fragmentação das cidades como bens ou produtos de consumo turístico constata-se a necessidade de valorização das características locais, das particularidades ambientais e socioculturais como forma de diferenciação mercadológica e inserção dos espaços urbanos no mercado de consumo turístico. Ao processo de planejamento do patrimônio cultural como produto, os sentidos e significados que definem os laços de pertencimento da comunidade em relação ao bem material ou simbólico que se pretende ofertar, tornam-se fundamentais para a revitalização das áreas urbanas com foco no desenvolvimento sustentável.

\section{POR UMA GESTÃo INTEGRADA E SUSTENTÁVEL DO PATRIMÔNIO CULTURAL}

Considerando o espaço urbano um sistema funcional dotado de organicidade, as ações de planejamento e gestão sustentável do turismo cultural necessitam de alternativas eficazes para promover a integralidade do patrimônio vivenciado no cotidiano das comunidades, compatibilizando-o com as demandas contemporâneas, tendo por objetivo formular e implantar alternativas viáveis para a promoção de um desenvolvimento endógeno e integrado.

A sustentabilidade cultural consiste em promover a multiplicidade de usos do espaço urbano, o incentivo às atividades artísticas e culturais, a criação de espaços públicos funcionais e interculturais, onde as comunidades possam desenvolver práticas de sociabilidade diversas, propiciando a reflexividade nas relações entre moradores e turistas e o favorecimento das identidades locais caracterizadas pelo espírito do lugar (PEIXOTO, 2003). 
O processo de reflexibilidade também é abordado por Jeudy (1999) que o entende como uma estratégia que confere um sentido e uma finalidade às ações de preservação patrimonial. Segundo o autor, esse processo consiste em promover a visibilidade pública dos patrimônios e dos lugares, assegurando a estrutura simbólica de uma determinada sociedade:

Para que exista um patrimônio reconhecível, é preciso que ele possa ser gerado, que uma sociedade se veja no espelho de si mesma, que considere seus locais, seus objetos, seus monumentos, reflexos inteligíveis de sua história, de sua cultura (JEUDY, 1999, p.19).

De acordo com Leite (2004), um espaço urbano torna-se um espaço público quando há um entrelaçamento entre as configurações espaciais e um conjunto de ações que permitam uma relação social e política entre seus freqüentadores, na medida em que lhe confere uma dimensão de singularidade e cria um sentido de pertencimento àquele espaço urbano em relação à comunidade local.

No âmbito das áreas patrimoniais, a sustentabilidade cultural alinha-se a um conjunto de estratégias no sentido de priorizar as especificidades do acervo arquitetônico, refuncionalizando-o por meio de ações que favoreçam o seu aproveitamento sustentável a partir das demandas comunitárias; a participação e o envolvimento da população residente nas propostas de revitalização do patrimônio cultural, primando pela co-responsabilidade dos atores públicos, privados e da sociedade; uma gestão cultural que propicie a valorização do patrimônio por meio de ações sócio-educativas e inclusivas e que ressaltem a sua importância como suporte da memória e das identidades locais, e ainda, o estabelecimento de limites em relação aos impactos ocasionados pela atividade turística nos espaços urbanos. Nesse caso,

A cidade retoma seus espaços não como signos vazios, apenas relatados na historiografia, mas como algo vivo, sempre em uso, necessário e amado, lugares de confluências de memórias passadas e, sobretudo, das memórias futuras (GRINOVER, 2007, p. 150).

Com base nessas diretrizes, o aproveitamento do patrimônio arquitetônico do bairro da Praia Grande implica a autodeterminação da comunidade local na sua reconfiguração como elemento de atratividade turística, respeitando seus anseios e necessidades, tanto no que se refere à salvaguarda de determinadas características, 
quanto à assimilação de conteúdos, elementos ou tecnologias decorrentes do intercâmbio de informações propiciado pelos fluxos transculturais que reorientam as produções locais, suscitando transformações.

Em virtude de se tratar de um fenômeno global e complexo que incide diretamente no cotidiano do núcleo receptor e nas formas de expressar a cultura e a identidade das populações envolvidas, o turismo pressupõe o aproveitamento do legado cultural de forma integrada, garantindo a preservação do patrimônio cultural com a necessária valorização da memória e identidade locais e o respeito às comunidades receptoras.

A vivência dos turistas com os referenciais da memória e da identidade de um lugar implica a utilização de instrumentos que possam contribuir para a sustentabilidade do turismo cultural. Nesse patamar, a ampliação do diálogo entre os órgãos de preservação patrimonial e a atividade turística torna-se fundamental no sentido de possibilitar maior acompanhamento e avaliação dos processos turísticos em áreas patrimoniais.

O planejamento e a gestão do patrimônio cultural pressupõem o estabelecimento de políticas públicas que conciliem as características dos bens culturais, sua dinamicidade, e as modificações que o uso turístico impõe, seja no ordenamento das cidades históricas, seja na adequação das manifestações populares às necessidades da demanda. $\mathrm{O}$ aproveitamento do patrimônio cultural para o turismo necessita da sistematização de novos instrumentais teórico-metodológicos, buscando-se uma atuação integrada e colaborativa entre os incentivadores turísticos e as comunidades locais.

A existência de planos e programas de recuperação de conjuntos arquitetônicos baseados nos laços materiais e imateriais tende a favorecer o estreitamento de vínculos afetivos entre a população residente e o patrimônio; ações de valorização da memória e da identidade local e de difusão das expressões populares, além de projetos sócioeducativos de interpretação do patrimônio local para a comunidade e grupos de visitantes, contribuem para a sustentabilidade cultural do patrimônio, a fim de conciliar os novos usos e significados que o patrimônio adquire nas sociedades contemporâneas. 


\section{CONSIDERAÇÕES FINAIS}

O bairro da Praia Grande reveste-se de um caráter cultural e espacial em que se refletem as ações do poder público local no que se refere ao gerenciamento das condições de existência e ao nível de ordenamento sócio-espacial; torna-se ainda cenário das relações sociais tradicionais e emergentes, lócus do sentimento de pertença da comunidade que cria uma identificação e um sentimento de apreço em relação a esse espaço urbano e ao seu entorno e, ao mesmo tempo, de estranheza em relação ao papel a ser desempenhado com o advento do turismo.

Em alguns momentos, as práticas governamentais inviabilizaram a permanência dos moradores tradicionais no bairro da Praia Grande ou provocaram o seu silêncio no âmbito das políticas de ativação patrimonial. Essas passaram a atender às novas demandas de lazer e consumo contemporâneos. Trata-se de um processo dinâmico balizado em mecanismos sucessivos de construção e reconstrução identitárias, nos quais os atores sociais se apropriam, selecionam e reelaboram determinados atributos culturais de acordo com os diferentes contextos ou momentos históricos, do qual a atividade turística constitui-se parte integrante.

A cultura recriada para atender ao mercado turístico acentuou uma mudança na percepção dos moradores em relação aos seus espaços de vida, contribuindo para a construção de uma nova imagem sobre o lugar Praia Grande, a qual se refletiu no nível de preservação do patrimônio edificado e nas relações compartidas entre moradores e visitantes.

A ressignificação do bairro da Praia Grande como elemento de atratividade turística conduz ao estabelecimento de novas relações entre a comunidade e os bens patrimoniais, produzindo novas territorialidades que afetam em maior ou menor grau o cotidiano local. Ainda, as discussões acerca da problemática da sustentabilidade urbana inserem a atividade turística no campo das disputas em torno da cenarização do patrimônio cultural como bem de consumo, sinalizando a necessidade de se promover maior diálogo entre o planejamento turístico e o planejamento urbano, no sentido de orientar as ações e minimizar os impactos negativos dessa atividade.

Baseado nesse delineamento, um conjunto de ações integradas de sensibilização e participação da comunidade, valorização, promoção e comercialização dos produtos 
culturais devem ser consentidas na perspectiva de promover novas experiências aos visitantes, aliadas às estratégias de interpretação do patrimônio cultural. Ressalta-se que o aproveitamento turístico dos espaços urbanos deve priorizar os significados dos bens patrimoniais para uma dada sociedade, além de incentivar atitudes de compromisso e de responsabilidade dos turistas e comunidades em relação ao patrimônio local.

\section{REFERÊNCIAS}

APPOLINÁRIO, F. Metodologia da Ciência: filosofia e prática da pesquisa. São Paulo: Cengage Learning, 2009.

ARGAN, G. C. História da Arte como História da Cidade. São Paulo: Martins Fontes, 2005.

ARANTES, A. A. Repensando os aspectos sociais da sustentabilidade: a conservação integrada do patrimônio ambiental urbano. In: Projeto História, 18. São Paulo: Educ/Fapesp, 1999, p. 121-134.

BARROS, A. J. da S.; LEHFELD, N. A. de S. Fundamentos de metodologia. São Paulo: Makron Books, 2000.

DENCKER, A. de F. M. Métodos e técnicas de pesquisa em turismo. São Paulo: Futura, 1998.

FREIRE, C. Além dos Mapas: os monumentos no imaginário urbano contemporâneo. São Paulo: SESC/Anablume, 1997.

GRINOVER, L. A hospitalidade, a cidade e o turismo. São Paulo: Aleph, 2007.

HALL, S. Da Diáspora: identidades e mediações culturais. Belo Horizonte: Editora UFMG; Brasília: Representação da UNESCO no Brasil, 2003.

JEUDY, H. P. Espelhos das cidades. Rio de Janeiro: Casa da Palavra, 1999.

LEITE, R. P. Contra-usos da cidade: lugares e espaços públicos na experiência urbana contemporânea. São Paulo: Ed. Unicamp, 2004.

LOUREIRO, F. J.; SANTIAGO, A. Desenvolvimento sustentável otimizado pela preservação dos centros históricos na sociedade globalizada, 2009. Disponível em: <http://www.arq.ufsc.br/infoarq/desenvolvimento_sustentável.html>. Acesso em: 14/10/2010.

LYNCH, K. A imagem da cidade. São Paulo: Martins Fontes, 1988. 
MAGNANI, J. G. C. Os diferentes planos da cidade como bem cultural. In: Patrimônio: atualizando o debate. São Paulo, IPHAN, 2006.

MENESES, J. N. C. História e Turismo Cultural. Belo Horizonte: Autêntica, 2004.

MENESES, U. T. B. de. A cidade como bem cultural - áreas envoltórias e outros dilemas, equívocos e alcances na preservação do patrimônio ambiental urbano. In: Patrimônio: atualizando o debate. São Paulo: IPHAN, 2006.

MINAYO, M. de S. Pesquisa social: teoria, método e criatividade. Rio de Janeiro: Vozes, 1994.

PEIXOTO, P. Centros Históricos e sustentabilidade cultural das cidades. Texto apresentando "A cidade entre projectos e políticas". Faculdade de Letras da Universidade do Porto, 2003. Disponível em: <http://www.ler.letras.up.pt/ficheiros/artigos 8511>. Acesso em: 09/11/2010.

SANTOS, M. A natureza do espaço: técnica e tempo, razão e emoção. 2. ed. São Paulo: Hucitec, 1996.

SCHULZ, S. H. Estéticas urbanas: da polis grega á metrópole contemporânea. Rio de Janeiro: LTC, 2008

SILVA, R. de A. Proposta do Governo do Estado do Maranhão para inclusão do Centro Histórico de São Luís na Lista do Patrimônio Mundial da UNESCO. São Luís: 1997.

SOTRATTI, M. A. A requalificação urbana e a mercantilização do patrimônio cultural: o caso do Centro Histórico de Salvador-Pelourinho. In: PAES, M. T. D.; OLIVEIRA, M. R. da S. (Orgs.). Geografia, turismo e patrimônio cultural. São Paulo: Annablume, 2010. p. 139-155.

SOUZA, C. F. de. Construindo o espaço da representação: ou o urbanismo de representação. In: SOUZA, C. F. de; PESAVENTO, S. J. (Orgs.). Imagens urbanas: os diversos olhares na formação do imaginário urbano. Porto Alegre: UFRGS, 1997. p. 107-122.

Recebido em: 29-01-2011.

Aprovado em: 01-03-2011. 